\title{
THE IMPACT OF STRATEGIC UK NATIONAL HEALTH SERVICE (NHS) FUNDING ON THE PATIENT RECRUITMENT TO 'ATHEROTHROMBOSIS' RESEARCH STUDIES. THE UK NHS ATHEROTHROMBOSIS RESEARCH NETWORK
}

A S Hall, ${ }^{1}$ D E Newby, ${ }^{2}$ C P Gale, ${ }^{1}$ R G Gillott, ${ }^{3}$ S Scarlett, ${ }^{4}$ S Wood, ${ }^{5}$ J D Gower, ${ }^{6}$ B Williams, ${ }^{7} \mathrm{M} J$ Caulfield ${ }^{7}{ }^{1}$ Leeds University; ${ }^{2}$ University of Edinburgh; ${ }^{3}$ Leeds General Infirmary; ${ }^{4}$ West Yorkshire CLRN; ${ }^{5}$ NIHR CV Specialty Group Coordinator; ${ }^{6}$ NIHR National Specialty Group Lead; ${ }^{7}$ NIHR CV Specialty Group Lead

doi:10.1136/heartjnl-2013-304019.27

Aim Atherothrombotic disease is endemic throughout the world. In the UK a new system for supporting clinical research was introduced in 2007 with the creation of the National Institute of Health Research (NIHR) which acts as the research arm of the National Health Service (NHS). In the current study our primary objective was to assess the impact of this important government initiative on patient involvement in research.

Methods All clinical studies that wish to have support from the NIHR funding stream have first to be adopted onto a central research portfolio. This process is 'automatic' for studies with specific recognised grant support, and is otherwise based upon an assessment by an expert panel. Information regarding study design and recruitment are collected at the time of adoption and then at
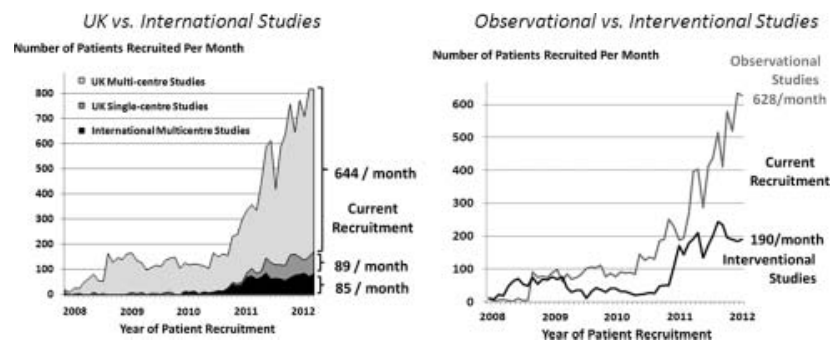

Figure 1

monthly intervals. Studies are allocated to an NIHR Clinical Research Network and to the relevant 'Specialty' which includes 'Cardiovascular' and within that to a subspecialty portfolio-in this case 'Atherothrombosis'. It is further noted if a study is (i) multicentre or single centre (ii) national or international (iii) observational or interventional.

Results The change in monthly recruitment between April 2008 and August 2012 is charted relative to study infrastructure (Panel A) and design (Panel B). Monthly recruitment rates have grown significantly to a maximum of 818 patients per month.

Conclusions Since the NIHR was set up along with the development of a NIHR Comprehensive Clinical Research Network (CCRN) which includes support for cardiovascular research within its remit, the number of patients involved in studies of atherothrombosis has increased substantially. The recruitment rate is currently around 800 patients per month, representing an increase of eightfold since April 2010. The coordination of research into atherothrombosis through a national networked approach, along with effective local mechanisms for delivering support and a system for directing funding based on previous recruitment performance has had a significant effect on the UK's capacity to undertake research into atherothrombosis. 